\title{
Experimental Investigation of Double Pipe Heat Exchanger by using Semi Circular Disc Baffles
}

\author{
Sarmad A. Abdal Hussein \\ Asst.Lect. Department of \\ Mechanical Engineering \\ University of Baghdad
}

\begin{abstract}
A set of the experiments were carried out to investigate the turbulent flow and heat transfer behavior in a double pipe counter water flow heat exchanger with inserted semi circular disc baffles on the opposite distances from the outer surface of the length of the inner tube. The test section is a horizontal annular passage formed by two concentric tubes with an inner to outer diameter ratio of 0.3 . Heat is only transferred from the annulus to the inner tube while outer tube is well insulated. Semi circular disc baffle with dimensions of $18 \mathrm{~mm}$ outer radius, $6.25 \mathrm{~mm}$ inner radius, and $1 \mathrm{~mm}$ thickness are used in the present study. The effect of turbulence on heat transfer and pressure drop was compared with the values for smooth tube. The effect of semi circular disc baffle was depended on the basis of varying the baffle spacing. All the results and readings were compared with the standard data from the smooth tube. In the beginning we conducted the experiment without any baffle to get the value for plane heat exchanger and with baffles with varying baffle spacing (15 and 45$) \mathrm{cm}$. The effects of the baffle spacing and flow Reynolds number on the thermal performance were examined. Whenever it comes to enhance the heat transfer between the surfaces. The pressure drop does play an important role and becomes another important factor to be considered and to be kept in mind. The maximum value of performance ratio (efficiency enhancement) was found for insert with baffle spacing $(15 \mathrm{~cm})$. Nusselt number and friction factor are higher than smooth tube depending on the baffle spacing and mass flow rate of the working fluid. New correlations based on the present experimental data for predicting Nusselt number and friction factor for the heat exchanger with and without baffle have been proposed. The proposed correlations can predict the experimental data with average relative error of $\pm 7.8 \%$ for Nusselt number and $\pm 6.5 \%$ for friction factor.
\end{abstract}

\section{General Terms}

A: Area for heat transfer $\left(\mathrm{m}^{2}\right), \mathrm{Cp}$ : Specific heat at constant pressure $\left(\mathrm{J} / \mathrm{kg} .{ }^{\circ} \mathrm{C}\right)$, D: Hydraulic diameter $(\mathrm{mm})$, d: Tube diameter(m), f: Fiction factor, h: Heat transfer coefficient $\left(\mathrm{W} / \mathrm{m}^{2} .{ }^{\circ} \mathrm{C}\right), \mathrm{K}$ : Thermal conductivity of material $\left(\mathrm{W} / \mathrm{m} .{ }^{\circ} \mathrm{C}\right)$ $\mathrm{L}$ : Length of tube (mm), m: Mass flow rate $(\mathrm{kg} / \mathrm{s}), \mathrm{Nu}$ : Nusselt number, P: Pressure $(\mathrm{Pa})$, Pr: Prandtl number of working fluid, Re: Reynolds number of working fluid, $\dot{Q}$ : Average heat transfer rate $(\mathrm{J} / \mathrm{s}), \mathrm{T}$ : Absolute temperature $\left({ }^{\circ} \mathrm{C}\right), \mathrm{U}$ : Overall heat transfer coefficient $\left(\mathrm{W} / \mathrm{m}^{2} .{ }^{\circ} \mathrm{C}\right)$, v: Velocity of working fluid $(\mathrm{m} / \mathrm{s})$, y: Space between baffle and another $(\mathrm{mm})$ $\rho$ : Density of working fluid $\left(\mathrm{kg} / \mathrm{m}^{3}\right)$, Subscript Meaning; ave: Average, $c$ : Cold water, exp. : Experimental, h.Hot water, i: Inlet conditions, LMTD: Logarithmic mean temperature difference, o: Outlet conditions , theo. : Theoretical.

\section{Keywords}

Double pipe, Semi circular disc baffles Heat exchanger

\section{INTRODUCTION}

Heat exchangers are equipments that are commonly used to transfer heat between two fluids at different temperatures. They are essential components in engineering systems, ranging from the heavy industries, such as chemical, automotive, power or metallurgy, through the high technique ones such as electronics, to production of every day consumers goods like air conditioning systems, refrigeration, etc. The most popular are those of recuperative type. The fluids are physically separated by heat transfer surface and the heat is transferred from hot to cold agent [1].

Augmentation techniques usually employ baffles attached to the heated surface so as to provide an additional heat transfer surface area and to promote turbulence. The presence of baffles causes the flow to separate, reattach and create reverse flow. Recently, many investigations have been focused on the baffle-walled channel heat exchangers. Most studies discussed the optimal baffle geometry that enhance heat transfer performance for a given pumping power or flow rate. While the use of solid baffles results in significant heat transfer enhancement, the associated increase in pressure drop and higher local thermal stress at the root of the baffle is of concern. Thus warranting the exploration of the use of perforated baffles to enhance the heat transfer while keeping the pressure drop to a minimum.

[2] investigated experimentally the effects of the baffle alignment (in-line and staggered), Reynolds number, open area ratio, baffle pitch and baffle height on the heat transfer enhancement, friction factor, and the thermal performance for turbulent flow of air in a rectangular duct with perforated baffles. [3] carried out experiments to determine how a single baffle placed at the inlet of a rectangular channel affects heat transfer and friction characteristics. The baffle was mounted on the upper inner surface of the channel, and the channel base was heated by a constant heat flux. Two different clearance ratios and four baffle inclination angles were used. The performance analysis by the equal friction factor criterion showed that the use of the inlet baffle is not thermodynamically advantageous on the basis of heat transfer enhancement. [4] Investigated the local heat transfer characteristics and the associated frictional head loss in a rectangular channel with inclined solid and perforated baffles. A combination of two baffles of same overall size was used. The upstream baffle was attached to the top heated surface, while the position, orientation, and the shape of the other baffle were varied to identify the optimum configuration for enhanced heat transfer. [5] Investigated the turbulent flow and heat transfer behavior in an annulus with perforated discbaffles aligned along the inner heated tube surface. He examined the effects of the baffle spacing, the baffle open area ratio, and flow Reynolds number on the thermal performance of a horizontal annular passage formed by two 
concentric tubes with an aspect ratio (Di/Do) of 0.3 . [6] Studied the heat transfer and friction in rectangular ducts with solid and perforated baffles attached to one of the broad walls. The baffled wall of the duct was uniformly heated while the remaining three walls were insulated. Performance comparison with the smooth duct at equal pumping power shows that the baffles with the highest open area ratio give the best performance. [7] Explored the local heat transfer in a rectangular channel with baffles and analyzes the experimental results of baffles with different heights and pores in the event of five Reynolds numbers and three heating quantities. [8] Investigated experimentally the heat transfer augmentation in the double pipe heat exchanger by using a new kind of insert called twisted wire mesh. Create a high degree of turbulence resulting in an increase in the heat transfer and pressure drop. Also they are investigated the effect of the wire mesh insert on the heat transfer enhancement efficiency and they compared with the values for the smooth tube. [9] Studied experimentally the effect of turbulence on heat transfer \& pressure drop was compared with the values for smooth tube. The effect of baffles as inserts for tube side flow of liquid was also taken into account and again a comparative study was made on the basis of varying the baffle spacing. All the results and readings were compared with the standard data from the smooth tube. From the above analysis of the available literatures, it is clear that there were no investigations of enhancing heat transfer in the annulus with inserted semi circular disc baffles. Therefore, the objective of this work is to study the turbulent flow and heat transfer behavior in the annulus with inserted semi circular disc baffles on the opposite distances from the outer surface of the length of the inner tube, using water as work fluid. Experimental measurements were conducted to investigate the effect of spacing baffle $(y=15,45) \mathrm{cm}$ and the flow of the Reynolds number on the thermal performance.

\section{EXPERIMENTAL APPARATUS AND PROCEDURE}

The parts of the experimental setup are showed as a schematic diagram in Fig.1 and the photograph of test rig in Fig. 2 respectively. It is basically a two concentric annulus tubes heat exchanger consisting of an inner tube which is a galvanize tube of ID $=22 \mathrm{~mm}$ and $\mathrm{OD}=25 \mathrm{~mm}$, and an outer tube of $(\mathrm{PVC})$ tube with $\mathrm{ID}=53 \mathrm{~mm}$ and $\mathrm{OD}=61 \mathrm{~mm}$. The length of the heat exchanger is $2000 \mathrm{~mm}$. Pressure tapping to pressure tapping length is $2100 \mathrm{~mm}$. The apparatus is also equipped with two water flow meters having flow ranges of 0 20 LPM for continuously measuring and maintaining the particular water flow rate. There are two flow meters one for hot water flow measuring and another one for the cold water. The tank is connected to the cold water inlet which is supplied from cold water tank fixed at a level higher than the original two concentric tubes heat exchanger level. There is another tank of capacity $600 \mathrm{~L}$ which has an inbuilt heater and pump for providing hot water of a particular temperature at a particular water flow rate. The inlet and outlet temperatures of the inner and outer tubes are measured by using four asbestos sheath alumel - chromel (type K) thermocouples. The end of thermocouple wires connected with standard male plug in order to connect them with the digital thermometer. Water at room temperature was allowed to flow through the inner tube while hot water (set point $60^{\circ} \mathrm{C}$ ) flowed through the annulus side in the counter current direction. The pressure drop through the two points in the inner tube measured by manometer manufactured locally, as shown in the Fig. 3. Circular steel tube with semi circular disc-baffles is used in the present study with dimensions of $26 \mathrm{~mm}$ outer radius, 12.5 $\mathrm{mm}$ inner radius, and $1 \mathrm{~mm}$ thickness. The Fig. 4 illustrate the Semi circular disc baffles which are attached to the inner heated tube surface by a thin layer of thermal epoxy on the outer surface of the inner tube. After leaving $5 \mathrm{~cm}$ from both ends the rest 1.9 m length was marked in 12 parts for $15 \mathrm{~cm}$ baffle spacing and similarly 5 parts for $45 \mathrm{~cm}$ baffle spacing. The space between baffles is $15 \mathrm{~cm}$ in case 1 and $45 \mathrm{~cm}$ in case 2 . The inlet temperature at the hot and cold water sides were kept constant at $60{ }^{\circ} \mathrm{C}$ and $20^{\circ} \mathrm{C}$, respectively. The hot water flow rate was kept constant at $0.16 \mathrm{~kg} / \mathrm{s}$ throughout the experiment whereas the cold water flow rate was adjusted from $0.06 \mathrm{Kg} / \mathrm{s}$ to $0.18 \mathrm{Kg} / \mathrm{s}$.

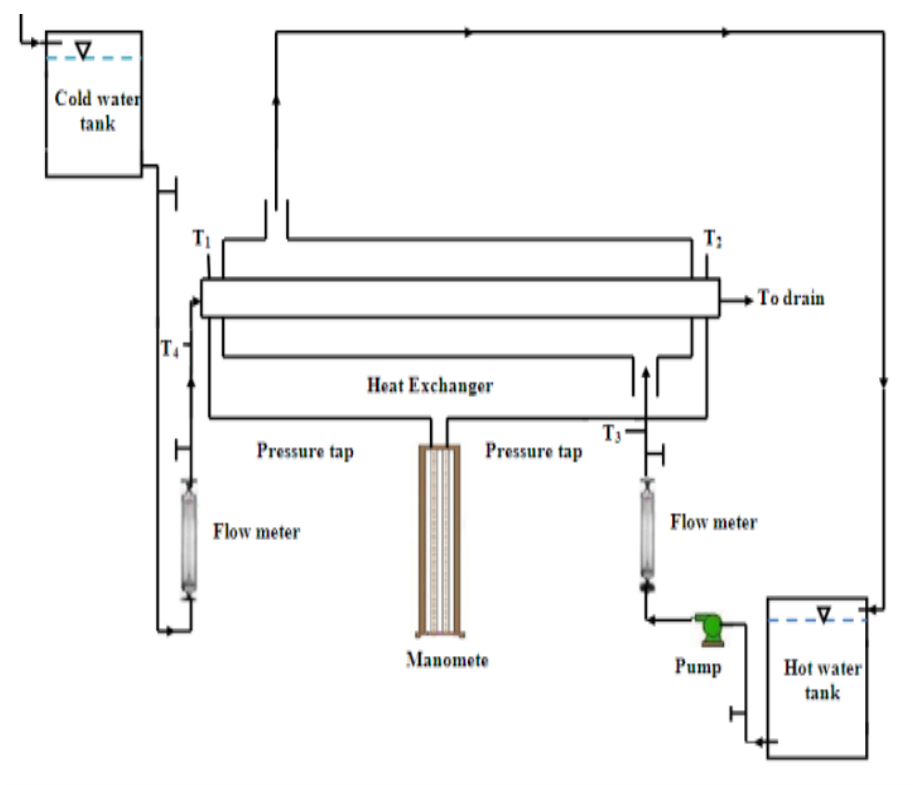

Fig. 1: Schematic diagram of experimental apparatus

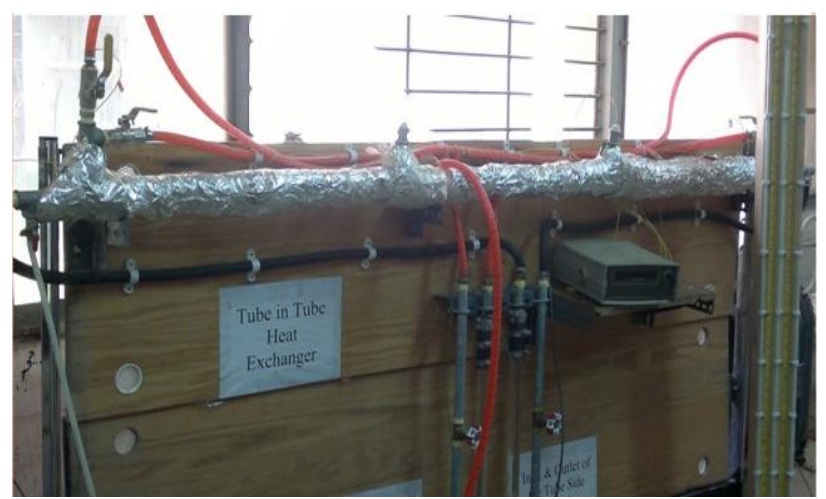

Fig. 2: the experimental apparatus.

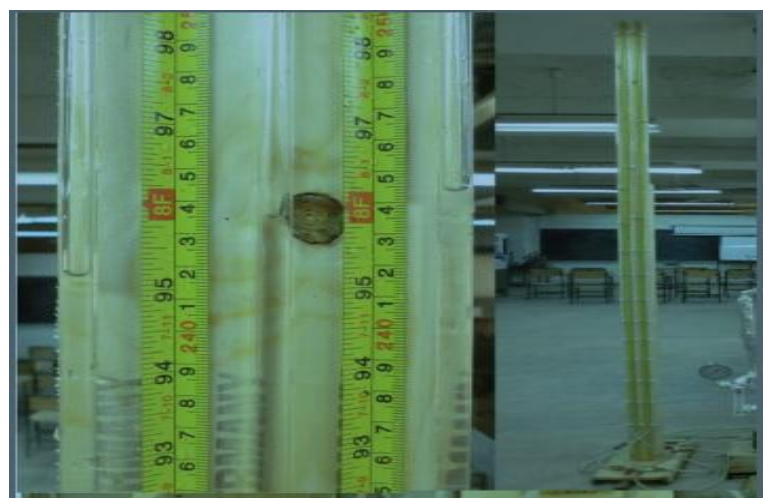

Fig. 3: Manometer components. 

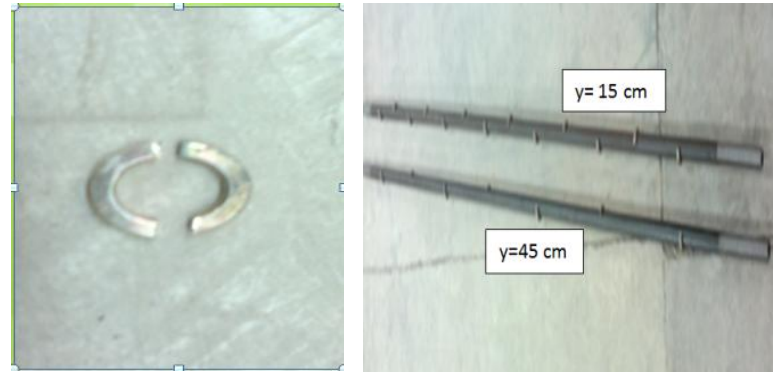

Fig. (4): Semi circular disk baffles with spacing between baffle and another $(y=15$ and $y=30) \mathrm{cm}$.

\subsection{Data Reduction}

The data reduction of the measured results is summarized in the following procedures:

Rate Heat transfer to the hot water, $\dot{Q}_{\mathrm{h}}$, can be calculated from

$\dot{\mathrm{Q}}_{\mathrm{h}}=\dot{\mathrm{m}}_{\mathrm{h}} \mathrm{C}_{\mathrm{p}, \mathrm{w}}\left(\mathrm{T}_{\mathrm{hi}}-\mathrm{T}_{\mathrm{ho}}\right)$

The rate heat transfer from the cold water, $\dot{Q}$ c, can be calculated from;

$\dot{\mathrm{Q}}_{\mathrm{c}}=\dot{\mathrm{m}}_{\mathrm{c}} \mathrm{C}_{\mathrm{p}, \mathrm{w}}\left(\mathrm{T}_{\mathrm{co}}-\mathrm{T}_{\mathrm{ci}}\right)$

The average rate heat transfer, $\dot{Q}_{\text {ave. }}$, of the hot and cold water can be determined from

$\dot{Q}_{\text {ave. }}=\frac{\dot{\mathrm{Q}}_{\mathrm{h}}+\dot{\mathrm{Q}}_{\mathrm{c}}}{2}$

The overall heat transfer coefficient, $\mathrm{U}$, is determined from the following equation;

$\mathrm{U}=\frac{\dot{\mathrm{Q}}_{\text {ave }}}{\mathrm{A}_{\mathrm{i}} * \mathrm{LMTD}}$

Where, $A_{i}=\pi d_{i} L$

The tube side heat transfer coefficient is than determined using;

$\frac{1}{\mathrm{U}}=\frac{1}{\mathrm{~h}_{\mathrm{o}}}+\frac{1}{\mathrm{U}_{\mathrm{i}}}$

Where the annulus side of heat transfer coefficient $\left(h_{o}\right)$ is estimated using the correlation of Dittus-Boelter [8].

$\mathrm{Nu}_{\mathrm{o}}=\frac{\mathrm{h}_{\mathrm{o}} * \mathrm{D}_{\mathrm{h}}}{\mathrm{k}}=0.023 \mathrm{Re}_{\mathrm{h}}^{0.8} \operatorname{Pr}_{\mathrm{h}}^{0.3}$

Where, $D_{h}=D_{i}-d_{o}$

The Reynolds number is based on the different flow rate at the inlet of the concentric tubes heat exchanger.

$\operatorname{Re}=\frac{\rho v d_{i}}{\mu}$

Thus the experimental value of Nusselt number is evaluated by,

$\mathrm{Nu}_{\text {exp } .}=\frac{\mathrm{h}_{\mathrm{i}} * \mathrm{~d}_{\mathrm{i}}}{\mathrm{k}}$

Theoretical value of Nusselt number without semicircular disk baffles (smooth tube) can be determined by using the correlation of Dittus-Boelter [8].

$N u_{\text {theo. }}=0.023 \operatorname{Re}_{c}^{0.8} \operatorname{Pr}_{c}^{0.3}$

Experimental friction factor can be written as: $\mathrm{f}_{\text {exp } .}=\frac{\Delta \mathrm{P} * \mathrm{~d}_{\mathrm{i}}}{2 \rho \mathrm{Lv}^{2}}$

$\mathrm{v}=\frac{\dot{\mathrm{m}}}{\rho * \mathrm{~A}_{\mathrm{i}}}$

Theoretical friction factor for smooth tube is calculated from the correlation of Blasius [9];

$\mathrm{f}_{\text {theo } .}=\frac{0.046}{\operatorname{Re}^{0.2}}$

All of thermo physical properties of the water are determined at the overall bulk temperature. The performance ration or enhancement efficiency $(\psi)$ is defined as the ratio of the heat transfer coefficient for the tube fitted with inserted semi circular disc baffles $\left(h_{c}\right)$ to that for the smooth tube $\left(h_{s}\right)$ at a constant Reynolds number (Re) as follows [10 and 11]:

$\Psi=\left(\frac{h_{c}}{h_{s}}\right)_{R e}$

\section{RESULTS AND DISCUSSION}

Fig. 5 and Fig. 6 Show the comparison of friction factor and Nusselt number with Reynolds number for smooth tube respectively. The experimental results are in agreement with the Dittus-Boelter correlation and Blasius Correlation. The experimental friction factor differs by about $17.8 \%$ from Blasius correlation, while the experimental Nusselt number differs by about $10.4 \%$ from Dittus-Boelte correlation. The Fig. 5 shows that Nusselt number considerably increases with increasing Reynolds number. The improvement of heat transfer with increasing Reynolds number is responsible by a decrease of thermal boundary layer thickness due to the promoted turbulent intensity. The turbulence augmentation has a great effect on pressure drop due to its action on wall shear stress. Therefore, the friction factors considerably decrease with increasing Reynolds as shown in Fig. 6.

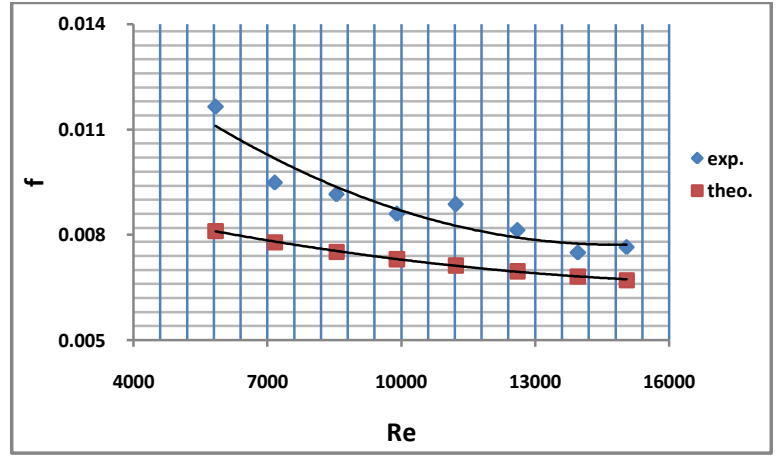

Fig. 5: Experimental \& theoretical friction factor versus Reynolds number for smooth tube

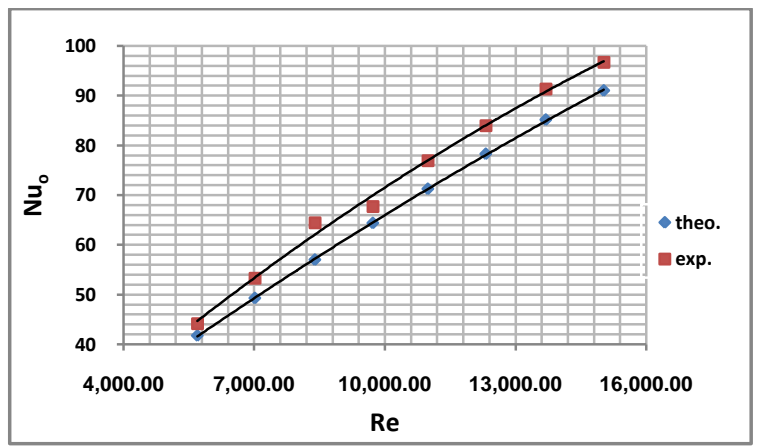

Fig. 6: Experimental \& theoretical Nusselt number versus Reynolds number for smooth 
The variation of friction factor with Reynolds number is shown in Fig. 7 which show that the friction factor decreases with increase in Reynolds number. The friction factor for inserted semi circular disc baffles is higher than the smooth tube and the decrease spacing between one baffle and another leading to higher friction factor because of the increase in the degree of turbulence and swirl flow on wall surface of the tube. Therefore, the inserted tape with $\mathrm{y}=15 \mathrm{~cm}$ has a maximum friction factor than that with $\mathrm{y}=45 \mathrm{~cm}$.

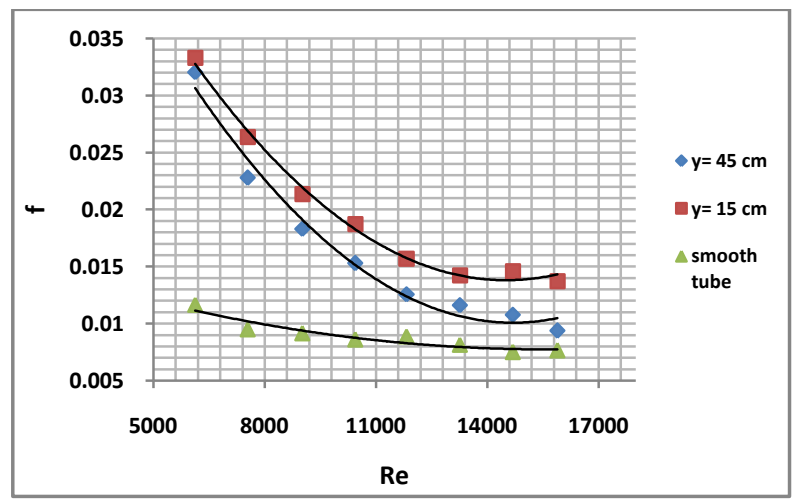

Fig. (7): Experimental friction factor versus Reynolds number for smooth tube and inserted semi circular disc.

Fig. 8 shows the variation friction factor ratio (the ratio represents the value for the experimental friction factor with semicircular baffles tube to that for smooth tube) as a function of Reynolds number. The figure show that friction factor ratio increases with decrease in the baffles spacing due to increase in swirl flow created with decreasing baffles space. The friction factor ratio is found to be highest for $y=15 \mathrm{~cm}$ and lowest in case of $\mathrm{y}=45 \mathrm{~cm}$.

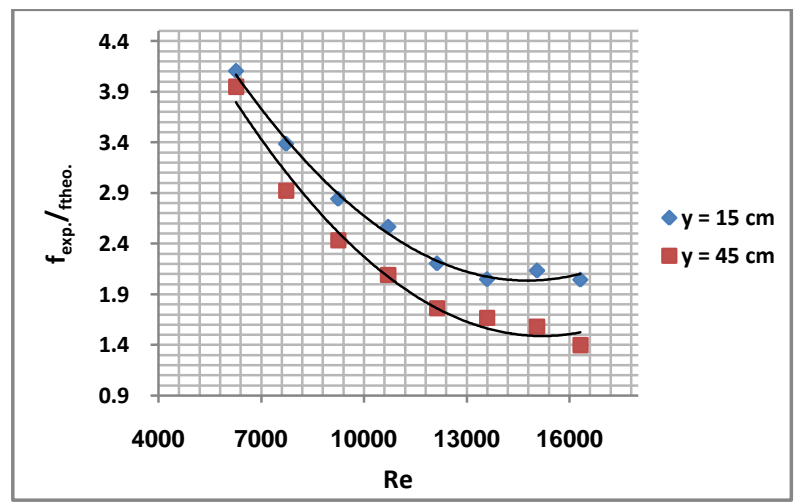

Fig. (8): friction factor ratio versus Reynolds number for inserted semi circular disc.

Fig. 9 indicates that the Nusselt number increases with increasing Reynolds number for smooth tube and inserted semicircular disc baffles $(y=15$ and 45$) \mathrm{cm}$. the Nusselt number for inserted baffles is higher than that for the smooth tube, because the presence of inserted semicircular disc baffles causes the dispersion and random movement of the flow field leads to higher heat transfer rate. In addition, it limits the growth of fluid boundary layer close to the heat transfer surface caused by periodic disruption of the layer due to repeated changes in the flow direction. As the baffle spacing (y) decreases a higher degree of turbulence is created and hence the heat transfer coefficient increases as the baffle spacing decreases. Over the range investigated the mean Nusselt number for inserted baffle spacing $(y=15 \& 45) \mathrm{cm}$ are 1.9 and 1.3 times the smooth tube respectively.

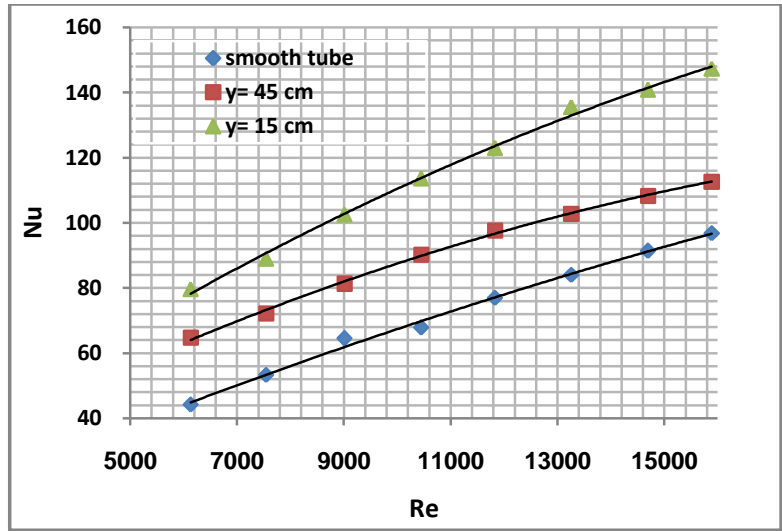

Fig. (9): Nusselt number versus Reynolds number for smooth tube and inserted semi circular disc.

The quality of enhancement concept is found from the performance ratio as shown in Fig. 10. The variation of performance ratio is observed for $y=15 \mathrm{~cm}$. from this it is concluded that the best arrangement is of $y=45 \mathrm{~cm}$. For all the cases, the performance of the semi circular disc baffle inserts are greater than unity which means that the application of enhancement is fruitful from the point of total energy saving and is higher than that of the conventional inserted baffle spacing as seen in the previous investigations in the literature survey.

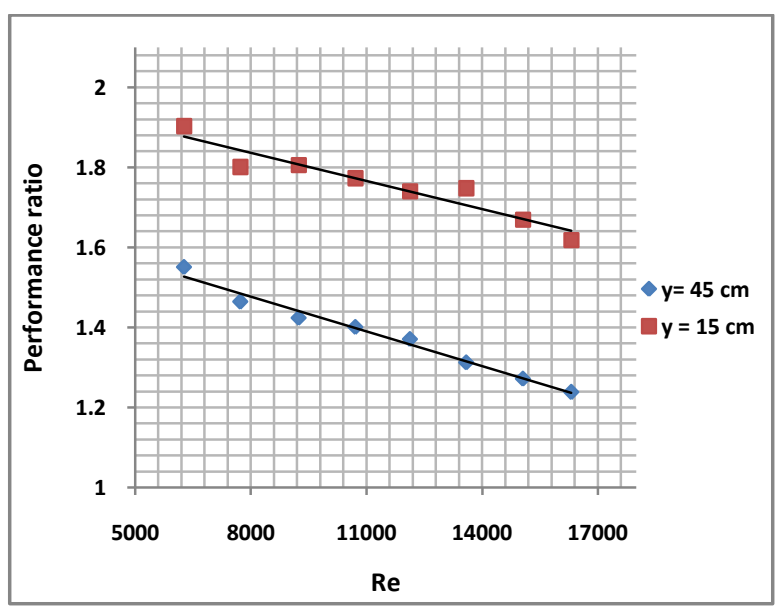

Fig. (10): Performance ratio versus Reynolds number for semi circular disc baffles.

Based on the present experimental data of the tube fitted with inserted semicircular disc baffles a correlation of Nusselt number related the friction factor and enhancement efficiency using polynomial- law approach.

$N u=31.36+1.03 * 10^{-7} R_{e}^{2}+0.0044 R_{e}$
$f=0.046+1.66 * 10^{-10} R_{e}^{2}-4.8 * 10^{-6} R_{e}$
$\Psi=1.2 * 10^{-8} R_{e}^{2}+0.0003 R_{e}-0.123$

Fig.11 and Fig. 12 show comparisons between the Nusselt numbers and friction factors obtained from the present experimental data and the presents predictions. In the figures, results of the present work reasonably agree well with the available correlations within $\pm 7.8 \%$ in comparison with experimental data for the Nusselt number and within $\pm 6.8 \%$ for the friction factor. 


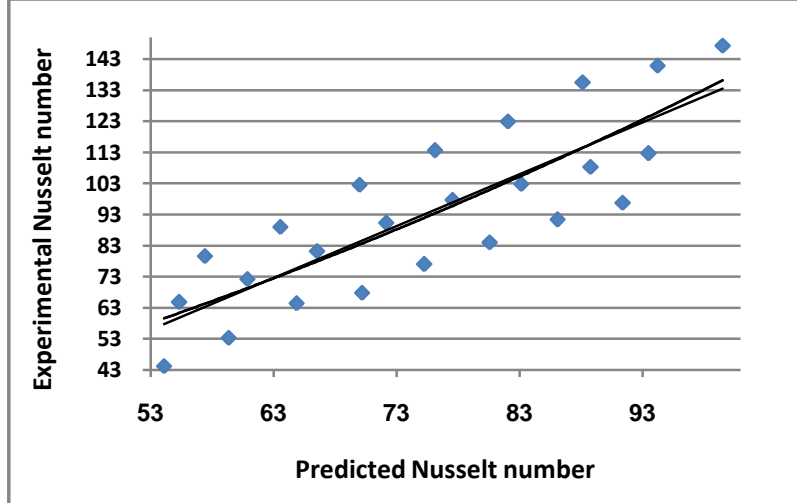

Fig. (11): Excremental Nusselt number versus predicted Nusselt number.

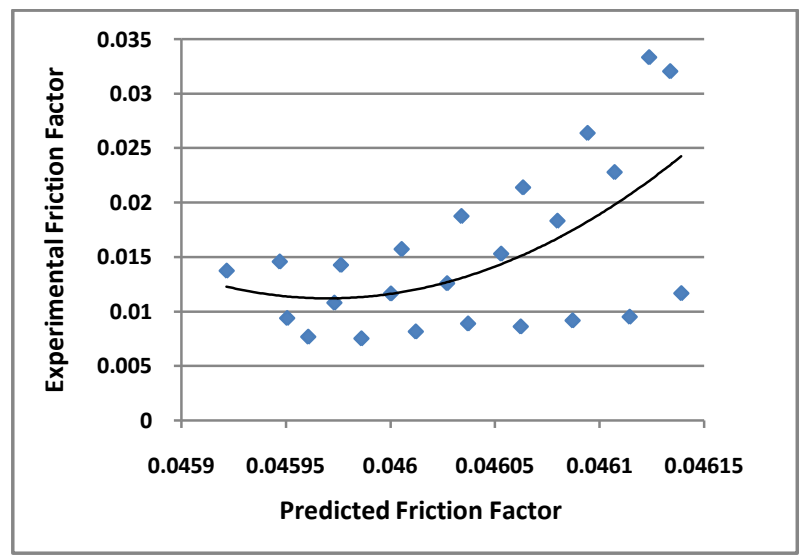

Fig. (12): Excremental friction factor versus predicted friction factor.

\section{CONCLUSIONS}

Experimental investigations of heat transfer and friction factor characteristics of double pipe heat exchanger fitted with inserted semicircular disc baffles with spacing of $15 \mathrm{~cm}$ and 45 $\mathrm{cm}$ carried out for turbulent flow. The following conclusion could be made:

- The heat transfer coefficient and friction factor increases with the decrease in baffle spacing compared with smooth tube.

- Inserted semicircular disc baffle (15 and 45$) \mathrm{cm}$ proves the heat transfer rate by 1.9 and 1.3 times that of smooth tube respectively.

- A good agreement is obtained between the experimental results and the new correlation of Nusselt number and friction factor for inserted semicircular disc baffle.

- The performance ratio for inserted baffle is greater than unity, therefore improvement in the energy saving lead to validate the capacity of the proposed expressions to predict the behavior for practical applications.

\section{REFERENCES}

[1] Nawras Shareef Sabeeh, Nawras Shareef Sabeeh,"Thermo-Hydraulic Performance of Horizontal Circumferentially Ribbed Double Pipe Heat Exchanger", Journal of Engineering and Development, Vol. 18, No.3, May 2014, ISSN 1813- 78222.

[2] Afify, R. I., and Abd-Elghany, M. E., "Turbulence and heat transfer measurements baffles in circular pipe", Engineering over doughnut-and-disc Research Journal, Helwan University, El-Mattaria Faculty of Eng., Cairo, Egypt, Vol. 52, pp. 1-20, 1997.

[3] Yilmaz, M., "The effect of inlet flow baffles on heat transfer", Int. Comm. Heat Mass "Transfer, Vol. 30, pp. 1169-1178, 2003.

[4] Dutta, P., and Hossain, A., "Internal cooling augmentation in rectangular channel using two inclined baffles", International Journal of Heat and fluid flow, Vol. 26, pp. 223-232, 2005.

[5] A. R. EL-SHAMY, "Turbulent Flow and Convective Heat Transfer in an Annulus with Perforated DiscBaffles", Eighth International Congress of Fluid Dynamics \& Propulsion 2006, Sharm El-Shiekh, Sinai, Egypt, Paper No.: EG- 185.

[6] Karwa, R., Maheshwari, B. K., and Karwa, N., "Experimental study of heat transfer enhancement in an asymmetrically heated rectangular duct with perforated baffles", International comm. in Heat and Mass Transfer, Vol. 32, pp. 275-284, 2005.

[7] Lin, C. W., "Experimental study of thermal behaviors in a rectangular channel with baffle of pores", International comm. in Heat and Mass Transfer, Vol. 33, pp. 985-992, 2006.

[8] Fuskele \& Dr.Sarviya, "Experimental Investigations of Heat Transfer Enhancement in Double Pipe Heat Exchanger Using Twisted Dense Wire Mesh Insert", International Journal of Advanced Engineering Research and Studies, IJAERS/Vol. 1/ 2005.

[9] Prof. S. K. Agarwal \& Jitendra Kumar Patro, "Experimental Studies on Heat Transfer Augmentation Using TMT Rods with and without Baffles as Inserts for Tube Side Flow of Liquids", National Institute of Technology Rourkela - 769008, 2012.

[10] Ameer A. Jadoaa, "Experimental Investigations Heat Transfer and Pressure Drop Characteristics of Flow Through Circular Tube Fitted With Drilled Cut-Conical Rings", Eng. And Tech. Journal, Vol. 29, No.3, 2011.

[11] Yakut, K., Sahin, B., and Canbazoglu, S., "Performance and flow induced vibration conical ring turbulators", Applied Energy, 2004; 79(1):65-76. 